\title{
De almanach a almanak: um olhar sobre dois importantes almanaques
}

\author{
From almanach to almanak: looking over \\ two important almanacs
}

Dirceu Magri

Universidade Federal de Viçosa-UFV

\section{DoI}

https://doi.org/10.37508/rcl.2021.n46a468

\section{RESUMO}

Trata-se de reflexões sobre dois importantes almanaques: o Almanach royal, produzido na França a partir do ano de 1683, e o Almanak Laemmert, publicado no Rio de Janeiro a partir de 1844 . Buscou-se primeiramente comentar a origem desse "gênero", que só há pouco despertou o interesse dos pesquisadores. $\mathrm{Na}$ sequência, este estudo empenhou-se em traçar um perfil de ambas as publicações, concluindo por seu caráter essencialmente fragmentário, formato que prenunciou uma dissolução da totalidade justamente por querer buscá-la a todo custo, dando conta de tudo o que acontece, por exemplo, em um país.

PAlAVRAS-CHAVE: Almanaque, Almanach royal, Almanak Laemmert.

\section{Abstract}

These are reflections on two important almanacs: the Almanach royal, produced in France from 1683, and the Almanak Laemmert, published in Rio de Janeiro from 1844. First, we sought to comment on the origin of this "gender", which only recently aroused the interest of researchers. 
Subsequently, this study this study was committed to drawing a profile of both publications, concluding for its essentially fragmentary character, a format that foreshadowed a dissolution of the totality precisely because it wanted to seek it at all costs, giving an account of everything that happens, for example, in a country.

KEYWORDS: Almanach, Almanach Royal, Almanak Laemmert.

\section{Introdução}

Objeto de numerosos trabalhos entre historiadores e estudiosos da história da literatura, o almanaque, ignorado por muito tempo, só recentemente começou a desfrutar da atenção dos pesquisadores. Por situar-se no entrecruzamento do documento de arquivos e do livro, acredita-se que esta particularidade tenha sido uma das razões pelas quais fora privado de interesse enquanto fonte de estudo. Combinado a isso, o estudioso depara-se com um material muitas vezes conservado em acervos de filosofia e história das bibliotecas (BARBIER, 2020), às vezes em local destinado a registros de algum valor histórico, porém não tão evidentes que possam aguçar o interesse do especialista ${ }^{1}$, até mesmo porque o almanaque não se inscreve entre os cânones das fontes históricas, a exemplo de relatos de guerras, tratados entre países, decretos reais, a cartografia e a epistolografia das figuras históricas etc. Por outro lado, a preteribilidade a que foi sujeitado tem a ver com o fato de o almanaque ser um material de consulta fastidiosa. Ainda segundo Barbier, o tamanho da fonte utilizada é muito pequeno o papel é de má qualidade e quando o pesquisador se dispõe a consultar a série completa de determinado almanaque, raramente encontra todos os números, pois o editor não se atentava à obrigatoriedade do depósito legal.

1 Vale ressaltar que em dias atuais a digitalização e a disponibilização dos acervos on-line facilitaram a busca do pesquisador, de modo que tais impedimentos não mais se justificam. 
O fato é que o almanaque é uma fonte rica em informação. Comentar a sua história ao longo da circulação das ideias, literárias ou não, é retroceder aos tempos de antanho, como diria o poeta, aos Les travaux et les jours (Os trabalhos e os dias), poema de Hesíodo, do século VIII a.C, verdadeiro tratado de navegação, agronomia e moral, de modo que não avançaremos sem antes tratar brevemente da sua etimologia: provavelmente derivada do árabe al manâkh, que significa "contar" e, em um sentido mais estendido, "livro de contas”, a palavra pode ser encontrada desde o século XIII, quando o matemático e astrólogo marroquino, Ibn el Bannâ de Marrakech, utilizou-a com o significado de "mesa composta de efemérides do sol e da lua" (RENAUD, 1947, p. 44-46). Contudo, os gramáticos não chegaram a um acordo sobre a origem da palavra: alguns a fazem vir da partícula árabe al manâkh - como mencionado acima -, enquanto outros, como Scaliger, afirmam que deriva da mesma preposição, al, e da palavra grega $\mu \alpha ́ v \alpha \kappa o s$, que significa “ao longo dos meses" (L'Encyclopédie, p. 290, t. I) ${ }^{2}$.

Estreitamente ligados à invenção da imprensa, desde o século XV os almanaques tornaram-se uma leitura bastante popular e superada apenas pela Bíblia, que sempre manteve a liderança das obras impressas mais lidas. Muitos eram recheados de desenhos e pinturas justapostos aos textos para que pudessem ser "lidos" por pessoas analfabetas. Não só os santos do dia, mas as colheitas e produtos das estações, contos, fait divers, coincidências estranhas, informações astrológicas e previsões meteorológicas, fatos curiosos e históricos, pensamentos positivos, receitas de iguarias, conselhos para horticultores, cuidados com as flores, remédios caseiros usados pelos antigos e uma infinidade de outros conhecimentos eram encontrados nas páginas dos almanaques.

2 Outros dados sobre a etimologia da palavra "almanach" podem ser encontrados em https://www.lalanguefrancaise.com/dictionnaire/definition/almanach . 
Havia também os almanaques de cunho espirituoso e burlesco que fizeram moda nos séculos XVI e XVII. Tratava-se de obras de caráter humorístico e satírico que retomavam a sequência do calendário para o ano seguinte, dentre as quais destacavam-se o Pantagrueline prognostication, de François Rabelais (1533), as Predications for the year, por Jonathan Swift (1708) e L'Almanach du Bonhomme Richard, de Benjamin Franklin (1732). Porém, dentre uma série de outros títulos $^{3}$ não dedicados ao humor, o almanaque que mais se destacou foi o Almanach royal, cuja publicação se iniciou no ano de 1683 e se estendeu até 1919, série contínua que ao longo do tempo teve seu título alterado.

\section{O Almanach royal}

Criado em 1683, o Almanach royal manteve esse título até o ano de 1792. No ano seguinte, passa a ser publicado como Annuaire impérial, ganhando ainda outros diferentes títulos até 1919, data do seu desaparecimento. $\mathrm{O}$ anuário, termo pelo qual também era conhecido, trazia em ordem de precedência o nome de todas as personalidades do reino: da família real aos príncipes de sangue, oficiais, marechais, embaixadores, alto membros do clérigo e figuras importantes da sociedade francesa. Em consonância às características próprias do

3 Almanach de liège (1626), Étas de France (1644-1789), Calendrier de la cour de Bruxelles (1719-1794), Les spectacles de Paris (1751-1797), Almanach de Gotha (1763), Almanach historique et chronologique de Languedoc et des provinces du ressort du Parlement de Toulouse (1755-179o, intermitentes), Almanach de Muses (1765-1833), Almanach de Paris (1772), Almanach Vermont (1886), Le grand messager boiteux de Strasbourg (1814), Le messager boiteux, almanach romand (1707), Almanach du Pèlerin, Almanach du Jura (1885). Hans-Jürgen Lüsebrink, em Le livre aimé du peuple: les almanachs québécois, de 1777 à nos jours (2014), menciona mais de 155 títulos de almanaques impressos fora da França. 
almanaque, apesar de sua "realeza" 4 , não era atrativo e convidativo à leitura, uma vez que trazia listas e mais listas normativas - e enfadonhas -, porém, tinha larga difusão entre um público leitor composto por juristas, conselheiros de Estado, banqueiros, além daqueles que se interessavam pela organização administrativa do Estado. Contudo, Grand-Carteret, em Les almanachs français, afirma que "a publicação típica deste período, pomposa entre todas, é o Almanach royal, que pelo seu próprio título confirma a tomada de posse do país pelo Rei e relega a segundo plano o l'État de la Frances." (1896, p. XXVI) .

Idealizado por Laurent d'Houry, suas primeiras edições não continham mais que algumas páginas com um calendário e presságios para o ano que se iniciaria. Pouco mais de uma década e o Almanaque já trazia algumas das extensas listas enumerando membros da nobreza e da aristocracia francesa, algo que se tornaria um dos seus constitutivos. Não à toa, em 1699, a viúva de d'Houry comenta nestes termos os primórdios da publicação:

Luís XIV, de gloriosa memória, por ter desejado este Almanaque, mandou que o pedissem ao autor, que teve a honra de apresentá-lo

4 Sua edição era em formato In-oitavo (in- $8^{\circ}$ ) - equivalente a um livro de bolso, tamanho 14×21cm, com capa de couro adornada com um ramo de lírios dourados. 5 Tratava-se de um anuário cuja ambição era trazer uma visão panorâmica dos órgãos administrativos que constituíam o reino da França. De publicação intermitente, aparece em 1619, assim como são vários os editores que se responsabilizaram por suas diferentes edições. Composto por cinco volumes de fólio, é muito superior em informação e conteúdo ao Almanach royal, mas por ser pesado ao manuseio, a dificuldade e o alto custo de produção afastaram os editores; já os leitores preferiram o Almanach royal, mais sucinto, de fácil manejo e menos oneroso.

6 "Toutefois, la publication type de cette époque, pompeuse entre toutes, c'est l'Almanach Royal, qui par son titre même, confirme la prise de possesion du pays par le Roi et rélègue à l'arriére plan l'État de France." 
a Sua Majestade. Isto o determinou, desde 1699, a atribuir-lhe o título de Almanaque Real, e a fazer deste trabalho uma das suas principais ocupações. ${ }^{7}$

Vale ressaltar o contexto em que a publicação, conhecida apenas por Almanach, passa a ter sua identidade ligada à realeza, tornando-se então o Almanach royal. À época, a corte de Luís XIV sofre intensa hierarquização, dado que se acentua com a ampliação do Château de Versailles, em 1684 (LAVISSE, 1983, p. 221-222), razão pela qual aos parisienses - e franceses de modo geral - são oferecidos nada menos que três anuários: o Calendrier de la cour, de Jean Colombat, o L'État de la France, de Louis Tribouillet e o Almanach royal, cuja primeira edição sob o novo título dá-se em 1700. As listas, elemento de base de todos os almanaques, explicam-se pelo fato de à época o reconhecimento dos pares figurar como um bem precioso e, não raro, objeto de ostentação e inveja, haja vistas as publicações afirmarem publicamente as vontades e o querer "oficial” do rei nomear seus cortesãos aos cargos criados para mantê-los ao seu lado, em Versalhes, algo que despertava os ciúmes de uns contra outros, conforme comenta Lavisse (1983, p. 225):

"Se alguém acaba de ser colocado em um novo posto, é uma efusão de elogios a seu favor, que inunda os pátios e a capela, que ganha a escadaria, as salas, a galeria, todo o apartamento"; mas é

7 "Louis XIV, de glorieuse mémoire ayant souhaité cet Almanach, le fit demander à l'Auteur, qui eut l'honneur de le présenter à Sa Majesté, dès 1699, sous le titre d'Almanach Royal; ce qui le détermina à faire de ce travail une de ses occupations." - Informação disponibilizada na p. 2 do Almanach royal de 1746. Disponível em : https://books.google.com.br/books?id=geCaK3zHWwo$\mathrm{C} \&$ printsec $=$ frontcover $\& \mathrm{hl}=\mathrm{fr} \# \mathrm{v}=$ onepage\& $\mathrm{q} \& \mathrm{f}=$ false. Acesso em: 16/o8/2021, às 15 h3om. 
aí que então “a inveja e o ciúme falam como adulação”, os quais, no entanto, torturam as almas. ${ }^{8}$

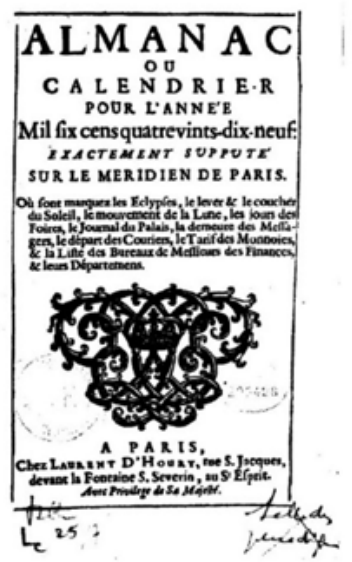

IMAGEM 1

página de rosto - Edição de 1689

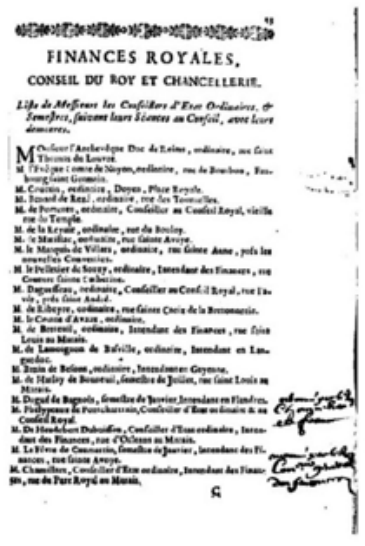

IMAGEM 2

exemplo das listas que compunham os almanaques - mesma edição

O Almanach royal e o Calendrier de la cour coexistiram pacificamente por uma década, enriquecendo seus editores, mas, a partir de 1710, Laurent d'Houry inclui em seu anuário seções bastante semelhantes àquelas publicadas no Calendrier. O conflito com Colombat se acirra quando d'Houry publica o seu Almanach abrégé, que não só mantém as seções, mas retoma o formato do Calendrier e move um processo contra seu concorrente. Como resultado, em sentença proferida d'Houry é obrigado a abandonar seu Abrégé e deixar de "plagiar" o Calendrier, ao passo que Colombat é obrigado a manter o

8 "Si quelqu'un vient d'être placé dans un nouveau poste, c'est un débordement de louanges en sa faveur, qui innonde les cours et la chapelle, qui gagne l'escalier, les salles, la gallerie, tout l'appartement”; mais c'est qu'alors “ l'envie et la jalousie parlent comme adulation”, elles n'en torturent pas moins les âmes. 
seu formato e impedido de aumentar o conteúdo de sua publicação, o que deixa o caminho aberto ao Almanach royal.

Ainda que tivesse o aval real ${ }^{9}$, publicar um almanaque sempre implicava correr algum risco. Em 1708, Laurent d'Houry foi perseguido por ter aberto uma tipografia em sua casa, sendo obrigado a vender todo o seu material. Em 1716, foi encarcerado na Bastille, em razão de uma queixa do conde de Stairs, embaixador da Inglaterra, que o acusou de haver "desrespeitado, no seu almanaque, o rei Georges, por não o nomear rei da Inglaterra, ou melhor, da Grã-Bretanha, e por mencionar como rei o filho de Jacques II Stuart, exilado em Saint-Germain" (CHARPENTIER, 1789, p. 62).

Quando Laurent d'Houry morreu em 1725, sua família, sem recursos, vivia sérios problemas econômicos, principalmente porque as receitas com a venda do Almanaque já não eram suficientes para cobrir as despesas da gráfica e da livraria, situação em que Élisabeth Dubois, sua viúva, assume o negócio. Charles-Maurice, o filho, que até então tinha sido apenas um simples revisor do Almanaque, tenta afastar a sua mãe por meio de um processo na justiça. Ele prepararia a edição de 1726, mas uma decisão judicial o proíbe não apenas de publicá-la apenas em seu nome, mas intervir nos negócios de sua mãe e de participar direta ou indiretamente na elaboração do Almanaque. Élisabeth Dubois ainda querelaria contra Colombat por duas outras vezes, mas os processos foram encerrados com a morte dos dois (LEPREUX, 1911, p. 140-144).

O fato é que antes, em 1728, Élisabeth Dubois já havia se associado a seu neto, André-François Le Breton, então com 18 anos e órfão sob a tutela de Charles-Maurice d'Houry, haja vista o rapaz haver herdado de d'Houry, por testamento, metade dos direitos do Almanaque, sen-

9 Tais publicações traziam na folha de rosto a inscrição "Avec Privilège de Sa Majesté", como mostra a figura 1. 
do que a outra metade havia sido destinada à sua viúva (LEPREUX, 1911, p. 301-302). Sob sua liderança, o Almanaque ganha nova vida e se enriquece com novas seções, o que não significa que não tenha enfrentado percalços com intelectuais e políticos, a exemplo de Voltaire que, em 1768, lhe envia uma carta incendiária por discordar de um comentário em sua publicação e também em 1774, quando as condições climáticas dificultaram a safra de trigo na França e o preço subia desproporcionalmente. A causa, segundo os boatos, era que o governo detinha o monopólio do trigo, de modo a manter as commodities altas. Le Breton publica os tais boatos no Almanaque e acrescenta um “Tesoureiro dos grãos à conta do Rei” na pessoa do Sr. Mirlavaud. Embora a edição tenha sido aprovada pela Chancelaria, Le Breton foi obrigado a fechar a sua tipografia por três meses e a publicar uma edição corrigida sem a linha litigiosa (COQUEREAU, 1777, p. 207) . $^{10}$.

Em 1777, Le Breton foi novamente acusado de ter inserido informação considerada subversiva. Segundo seus detratores, em um artigo ele havia citado promotores e advogados do parlamento de Paris, ao comentar uma reforma parlamentar realizada por Maupeou. Como reprimenda, Le Breton foi obrigado a "cobrir" o artigo nos Almanaques que ainda não haviam sido vendidos e a substitui-lo gratuitamente àqueles que já o haviam adquirido. Le Breton morre em 1799 e deixa o negócio a seu primo, Laurent-Charles d'Houry, filho de Charles-Maurice d'Houry. Com a Revolução Francesa o privilégio concedido à família Houry foi ameaçado quando Camille Desmoulins, em seu Discours de la lanterne aux parisiens ${ }^{11}$, afirma que este passaria a Baudouin, outro editor parisiense, contudo, nota-se, a partir das publicações da época, que Baudouin encarregou-se dos

10 Existem duas versões do Almanach de 1774, com e sem o "Trésorier des grains au compte du Roi”, na página 553.

11 Panfleto redigido por Camille Desmoulins e publicado em forma de brochura em $15 / 09 / 1789$. 
impressos da Assembleia Nacional, de forma que a hegemonia da família d'Houry frente ao Almanach, criado em 1683, só terminaria definitivamente em 1814, quando a empresa foi transferida para a associação Guyot-Testu. Anne-Charlotte d'Houry, uma das últimas remanescentes a se envolver com a publicação, morreria em 1828, aos 83 anos de idade.

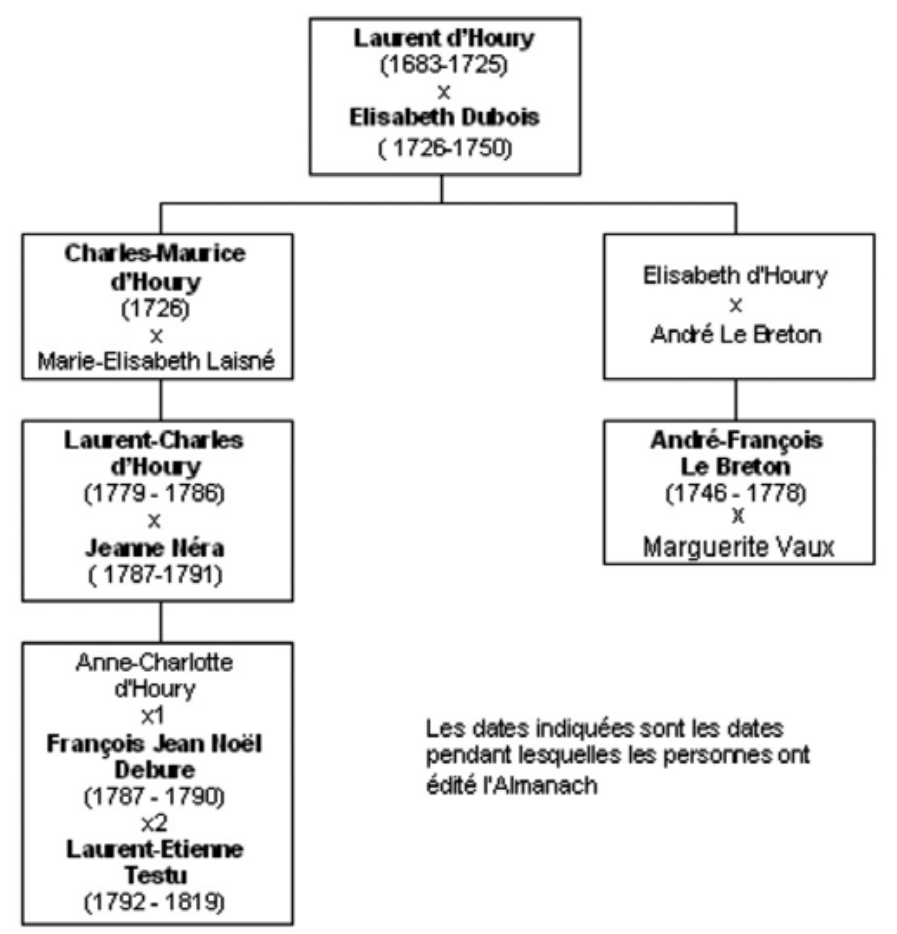

IMAGEM 3:

Fonte: https://commons.wikimedia.org/wiki/File:Almanach-royal-houry.gif

* As datas indicadas são aquelas durantes as quais as pessoas editaram o Almanach Royal

Em 1867, a edição do Almanaque foi transferida para a viúva Berger-Levrault, que já publicava o Annuaire diplomatique de l'empire français e o Annuaire militaire de l'empire français, ambos em formato de almanaque. O Almanaque deixou de ser publicado em 1919, após uma interrupção de quatro anos devido à guerra. O último número cobre os anos de 1915 a 1919. Não se sabe os motivos 
que levaram à descontinuação da publicação, mas especula-se que a combinação do tamanho do volume - mais de 1650 páginas em 1900 - e o difícil período que atravessava a economia e política francesas na época, tornaram a gestão e a produção de informações para o volume algo extremamente complexo e pouco rentável para ao editor. De qualquer modo, o título da publicação seria retomado pela família real dos Bourbons no ano de 1975. Em 2018, um blog orleanista publica na rede uma obra intitulada Almanach royal de la couronne, apresentado como continuação do Almanach royal de 1848. Em 2019, o blog Cercle d'union légitimiste de Normandie publica, também na internet, um Almanach royal para o ano bissexto de 2020 .

\section{O Almanaque Laemmert (e seus antecedentes)}

Muitos estudiosos argumentam que o Almanaque da Bahia teria sido o mais antigo a ser publicado no Brasil, contudo, se retornarmos às origens das tipografias no país, uma vez que, a exemplo da França, por aqui os almanaques também estiveram ligados ao desenvolvimento da imprensa, tal afirmação pode ser questionada. É senso comum afirmar que um folheto, intitulado Brasilche Gelt-Sack teria sido impresso no Recife, no ano de 1634, algo colocado em xeque pelo Professor José Marques de Melo (2003, p. 21), uma vez que pesquisas nos arquivos brasileiros e holandeses comprovaram que os impressos supostamente recifenses haviam sido produzidos em gráficas europeias.

O que se tem como certo é o nome de Antonio Isidoro da Fonseca, que, em 1746 , teria inaugurado a primeira tipografia no Rio de Janeiro, quando editou, em 7 de fevereiro daquele ano, um relato histórico de 24 páginas, in $4^{\circ}$, de provável autoria de um Luiz Antonio Rosado da Cunha, em cujo colofão indica a cidade do Rio de Janeiro, na segunda oficina de Antonio Isidoro da Fonseca, Anno de M.DCC. 
XLVII' ${ }^{12}$ (MAGRI, 2020, p. 38). O embargo por parte da Coroa à atividade de Fonseca foi rápido, obrigando-o a voltar a Portugal, de onde, em 1750 , tentaria mais uma vez retornar ao Brasil, mas sem sucesso.

Ainda que Laurence Hallewell (2005, p. 101) mencione um Almanaque da cidade de 1799, ao tratar da existência de apenas duas livrarias na cidade do Rio de Janeiro, a de Paul Martin e a de um incerto Brito, é bastante provável que este almanaque tenha sido impresso na metrópole. Foi necessário esperar até 1808, quando da transferência da família real, para que fosse instituída a primeira tipografia em solo nacional, mais precisamente no dia 13 de maio de 1808 , quando se publicou um folheto de 27 páginas, $295 \mathrm{~mm}$ de altura, em tipos equivalentes a 14 pontos (HALLEWELL, 2005, p. 110).

O Almanaque mais antigo disponível na Hemeroteca Digital (Coleção Digital de Jornais e Revistas da Biblioteca Nacional) traz na capa Almanach do Rio de Janeiro para ao anno de 1816 e, na parte inferior: "Rio de Janeiro. Na Impressão Regia. Com licença (o restante está ilegível)". Por essa razão, se houve um almanaque da Bahia é possível que se tenha perdido, sobrevivendo somente através de reminiscências literárias. O Almanach do Rio de Janeiro segue o modelo do Almanach royal, isto é, permeado de listas e mais listas que preenchem as suas 394 páginas. A primeira das listas (p. 3), intitula-se "Noticias Chronologicas. Epochas Geraes" e se inicia com uma linha do tempo: "Do período Juliano 6529", passa para a "Da creação do mundo segundo Usserio 5820, segundo Scaligero 5759, segundo Calvisio 5765, segundo Petavio 5799, o Diluvio universal 4164", avança para a $1^{a}$ Olimpíada em 2590 e a Fundação

12 Trata-se da Relação da entrada que fez o excellentissimo e reverendíssimo senhor D. F. Antonio do Desterro Malheyro, Bispo do Rio de Janeiro, em o primeiro dia deste prezente Anno de 1747, havendo sido seis annos Bispo do Reyno de Angola, donde por nomiação de Sua Magestade, e Bulla Pontificia, foy promovido para esta diocese. 
de Roma em 2565 e 2560, segundo Varrão e Fabio Pictor respectivamente, para terminar na página 4 com a Elevação do Brazil a Reino. Na sequência tem início a lista dos "Dias de grande gala na corte, segundo as ordens de Sua Magestade" para, na página 11, iniciar uma série com os nomes dos reis de Portugal e, na página 26, ter início uma lista intitulada: "Corpo Diplomatico. Embaixadores, Ministros plenipotenciarios, e encarregados de negócios de SUA MAGESTADE FIDELISSIMA nas Cortes Estrangeiras". Depois disso, as listas se repetem mencionado as diferentes funções dos colaboradores do reino até fechar o almanaque.

$\mathrm{Na}$ década seguinte, entre os anos de 1820 e 1829, os almanaques começam a se particularizar e temos, além do Almanach do Rio de Janeiro, o Almanak dos negociantes do Imperio do Brasil (RJ) e o Almanak imperial do commercio e das corporações civis e militares do Imperio do Brasil (RJ). O primeiro registro de um almanaque impresso na Bahia em depósito na Hemeroteca Digital data de 1845 . Na capa, lê-se: Almanach para o anno de 1845 e, abaixo do brasão do Império, “Bahia: Na Typ. de M. A. da S. Serva”. A terceira página o Almanaque (da Bahia) traz um sumário (ver imagem 4), o que denota um avanço em relação ao Almanach do Rio de Janeiro ${ }^{13}$, por exemplo, que não apresentava qualquer índice.

13 O último Almanach do Rio de Janeiro disponível na Hemeroteca Digital é do ano de 1824 . Em 1878 apareceria um outro, agora intitulado Almanak popular do Rio de Janeiro, organizado por Dias da Silva Junior e editado pela Typographia Carioca. 


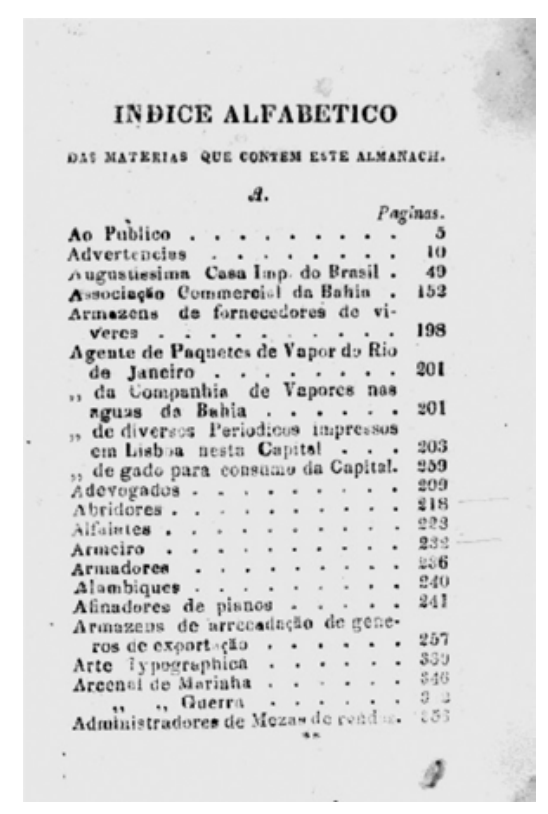

IMAGEM 4 - Almanach para o anno de 1845 p. 3-Bahia

O Almanaque Laemmert, como conhecemos hoje, tinha como título original Almanak Laemmert. Também era denominado Almanak administrativo, mercantil, e industrial do Rio de Janeiro e é comumente considerado o primeiro almanaque publicado no Brasil, algo que, conforme descrevemos acima, não se confirma. Editado no Rio de Janeiro pelos irmãos Eduard e Heinrich Laemmert, foi publicado entre os anos de 1844 e 1889. O Laemmert, a exemplo do Almanach royal, trazia textos sobre a corte brasileira e as já conhecidas listas com nomes de integrantes dos ministérios, a legislação, dados censitários etc. O Laemmert conta com 46 edições e cerca de 55 mil imagens, disponibilizadas pela Fundação Biblioteca Nacional ${ }^{14}$.

Pode-se presumir, dada as constantes menções a Baptiste-Louis Garnier (1823-1893) em estudos sobre a história do livro no Brasil,

14 Para mais consultas, acessar: http://objdigital.bn.br/acervo_digital/div_ periodicos/almanak/almanak.htm 
que o célebre livreiro, notabilizado por haver publicado grandes nomes da literatura brasileira, dentre os quais Machado de Assis, tenha reinado absoluto ao longo do século XIX. Contudo, os Laemmerts haviam se estabelecido no Rio de Janeiro há muito mais tempo que Garnier"15, haja vista "suas origens remontarem a 1827, data da abertura da agência conjunta com Bossange e Aillaud ${ }^{16 "}$ (HALLEWELL, 2005, p. 232). Ainda segundo Hallewell, Ludwig Christian Eduard von Laemmert (1806-1880) e seu irmão Heinrich Wilhelm Laemmert (1812-1884), filhos de F. W. Laemmert, um clérigo protestante de Rosenberg, grão-ducado de Baden, foram educados em línguas antigas e outros estudos visando a carreira comercial. Aos 14 anos, são transferidos para Karlsruhe, onde iniciariam o aprendizado no comércio de livros, quando Eduard começa a trabalhar com o impressor e livreiro Gottlieb Braun, e Heinrich com Marx, também livreiro.

Cinco anos depois Eduard partiu para Paris, onde conseguiu trabalho com Martin Bossange que, menos de dois anos depois, abriria uma filial no Rio de Janeiro. Em 1827, aos 21 anos, chega à capital do Império como representante do francês, junto de um português chamado Souza, que representava J. P. Aillaud, outro editor francês sócio de Bossange. A nova loja teve como endereço a rua dos Latoeiros - hoje Gonçalves Dias -, n. ${ }^{\circ} 88$, "com o nome de Souza Laemmert, vendedores de 'obras francesas modernas de filosofia, administração, artes, ciências, poesias"' (HALLEWELL, 2005, p. 233).

Findo seu contrato com Bossange, Eduard Laemmert decide se estabelecer no Brasil, atraído pelo liberalismo do regime e a ausência

15 Baptiste-Louis Garnier chega ao Rio de Janeiro, a bordo do Stanislas, em 24 de junho de 1844 .

16 Martin Bossange e Jean Pierre Aillaud, livreiros franceses. 
de censura. Em pouco tempo domina a língua portuguesa, casa-se com a filha de um deputado e abre seu próprio negócio na rua da Quitanda, n.o $77^{17}$, a Livraria Universal. Heinrich, o irmão, que à época já contava 29 anos, foi convencido por Eduard ${ }^{18}$ a transferir-se para o Brasil. Uma vez no Rio de Janeiro começa a trabalhar com o irmão, mas só em 1838 constituem sociedade com o novo nome de “E. \& H. Laemmert, mercadores de livros e de música”.

O êxito com a venda de livros fez com que, por volta de 1840, abandonassem a música, embora, segundo Hallewell (HALLEWELL, 2005 , p. 234), continuassem por algum tempo com a venda de águade-colônia e água de soda ${ }^{19}$. Começaram, de fato, com o trabalho de edição em 1839, com a publicação da Folhinha anual, uma miscelânea literária organizada por Eduard, que publicava muito material de sua autoria. A experiência acumulada com a Folhinha, levou-os, cinco anos depois, a publicar a primeira edição do Almanak administrativo, mercantil e industrial da corte e provincia do Rio de Janeiro que, depois, ficaria conhecido apenas por Almanak Laemmert.

17 Delso Renault, O Rio antigo nos anúncios de jornais (1969, p. 122), em nota de rodapé traz a seguinte informação: "Ernesto Sena (O Velho Comércio do Rio de Janeiro, Livraria Garnier, Rio de Janeiro) registra a chegada de Eduardo Laemmert e seu irmão Henrique em fins de ano, instalando uma livraria no nr. 77 da Rua da Quitanda; em 1840 fundaram uma tipografia, que começou na Rua do Lavradio, nr. 65 e depois foi transferida para a Rua dos Inválidos, nr. 93.”

18 Eduard e Heinrich, no Brasil, passariam a se chamar Eduardo e Henrique.

19 Cabe ressaltar que à época as casas de livros funcionavam como verdadeiros empórios, oferecendo uma diversidade de produtos que ia muito além de livros e artigos de papelaria. 


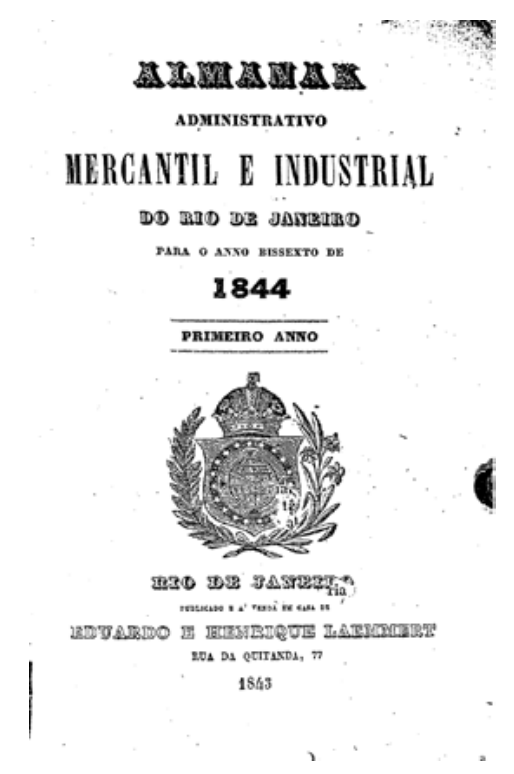

IMAGEM 5 - Capa da primeira edição do Almanak Laemmert para o ano de 1844 que, no entanto, apresenta en bas de page o ano de 1843 .

Ainda que não tenha sido o primeiro dos almanaques a ser publicado no Brasil, como vimos acima, o Almanak Laemmert, por ser mais completo, supera todos os seus concorrentes. Nelson Werneck Sodré, ao se referir ao Almanak, em História da imprensa no Brasil (1999, p. 206), afirma tratar-se de uma publicação tradicional e de tanto prestígio que continuaria "a ser publicado mesmo depois do desaparecimento da casa, que lhe dera o nome, distribuído por outras, até $1930^{\prime 20}$. Isso diz muito da qualidade do trabalho dos Laemmerts que, ao contrário de outros editores aqui estabelecidos - como Garnier -, que mandavam imprimir seus livros na França, os Laemmerts, no início os imprimiam na Alemanha, para depois imprimi-los em sua própria tipografia. Sobre isso, discorre Werneck Sodré, que ressalta o grande prestígio da casa:

20 Werneck Sodré afirma que Francisco Alves de Oliveira "compraria o Laemmert, em 1905, e recebeu Os Sertões, de Euclides da Cunha” (1999, p. 208). 
A casa Laemmert, afora o seu célebre Almanak, editaria obras de Direito, Medicina e Literatura e autores como Machado de Assis, Said Ali, Valentim Magalhães, Coelho Neto, Afonso Celso, as duas primeiras edições da História do Brasil, de Varnhagen, as três primeiras de Os Sertões, de Euclides da Cunha. (WERNECK SODRÉ, 1999, p. 206-207)

O fato é que o Almanak Laemmert, que em sua primeira edição perfazia um total de 288 páginas, na edição de 1889, totalizava 2122, com alguns decréscimos, haja vista ser composto de cinco partes e no final da parte IV, por exemplo, trazer a informação de que "as paginas 1677 a 1696 ficão reservadas para os accrescimos dos annos futuros" (LAEMMERT, 1889, p. 1676). Vale ressaltar que os irmãos Laemmert revelaram-se ótimos empreendedores: implantaram um setor gráfico com a importação de dois prelos na Alemanha e um outro adquirido no Brasil, de Gueffier ${ }^{21}$, e o próprio Eduardo volta a Paris por três meses para aprender a arte da tipografia nas principais editoras da capital francesa, donde especulou-se que iniciariam a publicação de um jornal. Em 1842, segundo Hallewell (2005, p. 234), o cunhado, Carlos Guilherme Haring (1813-1871), uniu-se aos irmãos e se tornou o gerente da nova tipografia e supervisor do Almanak até a sua morte.

A título de prefácio, a edição de 1844, traz uma “Advertencia dos Editores" (p. III-IV) que data de dezembro de 1843 e é assinada por Eduardo e Henrique Laemmert. Nela os autores destacam o caráter utilitário do Almanak, argumentando sobretudo que pouparia tempo ao público, pois este teria à disposição uma obra que figuraria como uma bússola na vastidão dos mares, evitando que perdesse tempo à procura dos profissionais e que retardasse o expediente de seus negócios:

21 Impressor francês estabelecido no Rio de Janeiro. 
Como argumento da utilidade de um Almanak para esta Côrte o que poderiamos nós dizer, que augmentasse no Publico esta convicção unanime; convicção fundada na quotidiana experiência?! Não fallemos já dos que em rasão de sua profissão teem de frequentar amiudadas vezes os estabelecimentos publicos e ou particulares, as Repartições Civis, Militares, Ecclesiasticas, \&c.; tratar com Procuradores, Advogados, Escrivães, com Empregados Publicos, Magistrados, \&c., \&c.; ainda aquelles, que não estimarão ter um Repertorio, que nas occasiões lhes dispensasse o andarem fazendo indagações, que lhes roubão tempo e multipicão passadas; quando não é que retardão e embaração o expediente de seus negócios, e até ás vezes os transtornão? E para os Provincianos que vem á Capital por qualquer respeito que seja; para esses é um Almanak tão indispensavel, como na vastidão dos mares é a Bussola ao maritimo. (LAEMMERT, 1844, p. III-IV)

Ainda na "Advertencia dos Editores", os irmãos Laemmert trazem a público terem considerado as muitas dificuldades que enfrentariam na concepção do Almanak e que para isso contaram com a ajuda de pessoas interessadas na sua elaboração, auxílio que se revelou algo enganoso, pois a "experiencia nos mostrou termo-nos em muito enganado" (LAEMMERT, 1844, p. IV), afirmam os editores, haja vista muito das informações terem se revelado "defeituosas, ou já tardias, posto que não prejudicasse a exactidão da obra" (LAEMMERT, 1844, p. IV), afora, continuam eles, terem contribuído para demorar " $\mathrm{a}$ publicação além do promettido" (LAEMMERT, 1844, p. IV).

Por outro lado, os Laemmerts reconhecem nas repartições públicas uma fonte "copiosa e exactissima" (LAEMMERT, 1844, p. IV) de informação, razão ela qual acreditam que seu almanaque levará grande vantagem sobre os demais já em circulação. Certos da produção de um bom material, colocam-se à disposição do público para eventuais correções, ainda que o trabalho tenha sido "fructo de incalculavel fadiga e (...) incançavel zelo bem geral” (LAEMMERT, 1844, p. IV). À vista disso, acreditam, alcançarão a indulgência dos leitores por 
alguma eventual imperfeição, caso em que prometem melhorar os almanaques futuros, indicativo de continuidade para a publicação.

Na sequência, ao menos na edição digitalizada do almanaque disponível no site da Hemeroteca Digital, parece haver a supressão de algumas páginas, da 1 a 34, haja vista a página subsequente, a 35, concluir uma lista com nomes de líderes de algumas nações. A página 36 se inicia com outra lista, agora a do "Corpo Diplomatico e Consular Estrangeiro Residente na Côrte do Rio de Janeiro", na qual figura o nome de Eduardo Laemmert, na condição de Consul de Baden, rua do Lavradio, 53. Depois, a lista da "Augustissima Casa Imperial do Brasil" (p. 39), seguida pelas "Casas Titulares do Imperio" (p. 40), os "Empregados do paço Imperial" (p. 45), "Ministerio do Imperio" (p. 67) e assim sucessivamente com as listas se desdobrando em nomes de todos os funcionários de todos os ministérios, da Municipalidade (p. 167), mencionando as Companhias, Sociedades e Institutos, Gabinetes de Leitura (p. 171), Conventos, Ordens Religiosas (p. 192), sendo estas por vezes interrompidas por "breves noticias" reportando a origem de algumas dessas ordens, além do relato da transferência de seus fundadores da Europa para o Brasil.

Teatros e casas de espetáculo também aparecem pouco antes da lista das "Profissões", espaço reservado para os profissionais liberais - de advogados a parteiras. Na página 216, inicia-se a lista do "Commercio", com o nome do estabelecimento, seu respectivo endereço, integrantes e, no caso de haver, seu corpo societário. Na página $25^{8}$, começam a ser mencionadas as "Autoridades da Provincia do Rio de Janeiro", seguida por um "Supplemento", com Leis do Orçamento para os anos de 1843 e 1844, a "Lista dos Srs. Assignantes não mencionados no corpo do Almanak" e um "Indice Alphabetico".

Estas listas, embora enfadonhas para o leitor atual, para o pesquisador revelam-se de fundamental importância. Jean-Michel Massa, por exemplo, grande pesquisador machadiano e autor de, 
entre outros, A juventude de Machado de Assis (1971), coloca em xeque a lenda de que Machado de Assis teria aprendido francês com o forneiro de Madame Galot, que tivera uma padaria à Rua São Luís Gonzaga e, para isso, Massa utiliza informações dessas listas produzidas pelo Laemmert:

No decurso de pesquisas bastante longas sôbre o problema, ficamos sabendo que entre 1850 e 1855 não existia a rua com êsse nome, que lhe foi dado sòmente em 1863. (...) Havia sem dúvida no número 33 da Rua do Pedregulho uma padaria, mas seu proprietário era Maria Rombo, que a conservou de 1856 a 1862, a acreditar-se no Almanaque Laemmert e nos guias do Rio dêsses anos. Só a partir de 1863 é que a viúva Margarida Galot surgiu pela primeira vez no mesmo enderêço. (1971, p. 74-74).

Se na edição de 1844 o índice ocupava cerca de 8 páginas do Almanaque, em 1968 totalizava 34 páginas e em 1889, última das edições disponíveis, nada menos que 79 páginas, o que diz muito do progresso alcançado pela capital do Império em 45 anos. A consulta do Almanak permite constatar ainda o cosmopolitismo da cidade, dada a quantidade de profissionais estrangeiros no país, o que se pode perceber também pela diversidade do comércio e serviços oferecidos aos cidadãos.

Vale empreender, contudo, um breve percurso pela página de rosto do Almanak, exercício que revela alterações no perfil da publicação, não só no título, mas também de seus colaboradores:

\section{Título:}

O título inaugural Almanak administrativo e industrial do Rio de Janeiro se manteria até o ano de 1847 , quando tem seu nome alterado para Almanak administrativo e industrial da corte e provincia do Rio de Janeiro; em 1872, passar a chamar-se Almanak administrativo e 
industrial da côrte e da capital da provincia do Rio de Janeiro com os municipios de Campos e de Santos; em 1873, à primeira parte do título (Almanak administrativo e industrial) acrescentou-se (da côrte e da capital da provincia do Rio de Janeiro inclusive alguns municipios da provincia, e a cidade de Santos); em 1875, (da côrte e provincia do Rio de Janeiro inclusive a cidade de Santos, da Provincia de S. Paulo], título que se manteria até 1882; em 1883, o Almanaque traria seu último título Almanak Administrativo e Industrial do Imperio do Brazil, com o seguinte subscrito: "Obra estatistica e de consulta, abrangendo todas as provincias do Imperio".

\section{Editores/Colaboradores:}

Nos anos de 1844 a 1847, os nomes de Eduardo e Henrique Laemmert só figuram na parte inferior da página de rosto, no espaço dedicado às informações do impressor (Tipografia) que, por coincidência, eram os próprios nomes dos editores, porém ambos assinam a "Advertencia do Editores", ou simplesmente "Advertencia" (em outras edições). A partir de 1848, nota-se a ausência de Henrique e Eduardo passa a tocar sozinho o projeto; nesse ano há na página de rosto a inscrição "Organizado e redigido por Eduardo Laemmert, Cavalleiro da Imperial Ordem da Rosa, Membro Correspondente do Instituto Historico e Geográfico de Sua Alteza Real o Grão-Duque de Baden”. Eduardo parecia alguém afeito à nomeada, não à toa sua titulação vai se alterando ao longo dos anos e é subscrita ao seu nome no Almanak. Assim, além do seu título de cavaleiro e de membro correspondente do Instituto Histórico, em 1851 aparece "Membro da Real Ordem Portugueza do Nosso Senhor Jesus Christo; em 1854, "Membro da Ordem Grão-Ducal Badense do Leon de Zaehringue"; em 1856, seu nome passa a ser grafado como Eduardo von Laemmert, sendo que o "von" sinaliza a origem, no caso, nobre; em 1857 , seriam acrescentadas "America Real Ordem Hespanhola de Isabel a Catholica" e "Imperial Associação Typographica Fluminense”; já em 
1868, quando Carlos Guilherme Haring assume a redação do Almanak, o nome de Eduardo aparece como fundador, seguido das titulações que remetem às suas ligações, digamos, mais políticas, a de Cavaleiro imperial e a de Membro do Instituto Histórico e Geográfico de Sua Alteza Real o Grão-Duque de Baden, para, em 1883, quando Arthur Sauer toma a frente do Almanak, não figurar qualquer titulação subscrita ao seu nome.

Carlos Guilherme Haring figura como redator a partir de 1860, com a subscrição "Cidadão Brasileiro"; em 1863, apareceria ainda "Actual Presidente da Imperial Associação Typographica Fluminense” e, em 1868, o título de "Cavalleiro da Imperial Ordem da Rosa", "Presidente Honorario da Imperial Associação Typographica Fluminense" e "Membro Effectivo da Sociedade Auxiliadora da Industria Nacional". Em 1872, sequer aparece o nome de Carlos Guilherme Haring, falecido no ano anterior. Em 1873, a página de rosto traz o nome de Eduardo Landim de Miranda, natural do Rio de Janeiro com "coadjuvado", estando à frente o próprio Eduardo Laemmert. Em 1876, seria a vez de José Antonio dos Santos Cardoso que aparece sob a subscrição de "coadjuvação", para, no próximo ano, figurar como redator até o ano de 1881 .

Em 1882, entraria em cena Arthur Sauer, cujo nome não aparece na página de rosto desta edição, mas que assina o "Prefácio" e reorganiza totalmente o Almanak. Sauer continuaria até a última edição do Laemmert, em 1899 ${ }^{22}$. Assim, Sauer inicia o prefácio à edição de 1882:

Achando-se impedido o Sr. J. A. dos Santos Cardoso de redigir o Almanak, por motivos de outros trabalhos importantes na Direcção de nossas Officinas, a que teve de dedicar exclusivamente a sua actividade, encarregou-se este anno o nosso socio o Sr. Arthur

221899 é o ano da última edição disponível na Hemeroteca Digital. A edição de 1867 foi removida do site da Hemeroteca Digital. 
Sauer da redacção e reorganisação do nosso annuario, que foi inteiramente reformado, classificado e organisado de novo.

No intuito de facilitar a consulta do Almanak, de modo a torna-lo mais util e principalmente mais pratico, tomámos a resolução de abandonar completamente o antigo systema de classificação.

A primeira decisão de Arthur Sauer foi não publicar mais anúncios de "fantasia, que se achavão intercalados nas diversas listas e artigos, tornando-os pouco claros" (LAEMMERT, 1892, p. V). Depois, padronizou a paginação, estabelecendo uma só para toda a obra, além de dividi-la em sete partes, sendo estas: 1) Calendario e nobreza brasileira; 2) Commercio e industria; 3) Administrativa; 4) Provincia; 5) Supplemento; 6) Accrescimos, emendas, alterações e mudanças vindas durante a impressão; 7) Notabilidades.

Vale destacar ainda: em 1850, o Almanak começou a publicar ilustrações com personagem da realeza ${ }^{23}$, ora brasileiras, ora estrangeiras, além de outras personalidades, como o próprio Eduardo Laemmert (imagem 6); em 1864, antes da página de rosto, inseriu algumas páginas com as “Obras necessárias a todos os cidadãos á venda na Livraria Universal de E. \& H. laemmert. Rua da Quitanda, 77”, um rápido merchandising para os negócios dos Laemmerts. O Almanak também trazia uma relação dos pontos de venda e distribuição da publicação, no Brasil, em diversos países da Europa, Estados Unidos e América do Sul (imagem 7).

23 Em 1850, por exemplo, aparece a ilustração de D. Amelia Duqueza de Bragança, Imperatriz viuva do Brazil, em 1854, o retrato do Imperador D. Pedro II. 


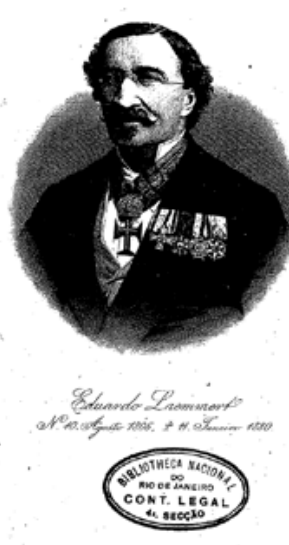

IMAGEM 6

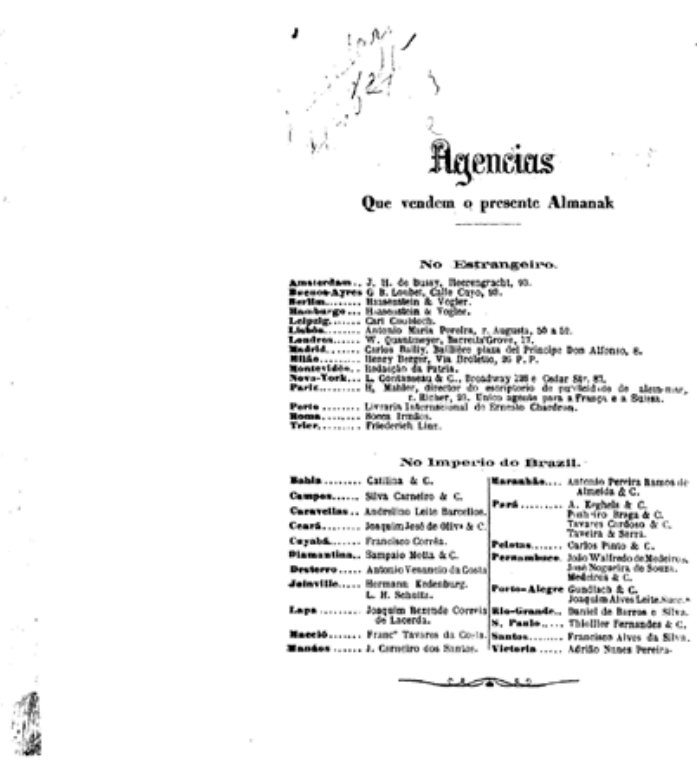

IMAGEM 7

Eduardo Laemmert, Edição de 1883 Pontos de venda, Edição de 1883

O Almanak continuaria o seu percurso nas mãos dos Laemmerts até o ano 1910, quando foi adquirido por Manuel José de Portugal, proprietário do Anuário geral de Portugal. Depois de alguns anos, recebe novo título, Anuário do Brasil, nome que segundo Hallewell (2005, p. 248-249) "passou a ser usado como marca das publicações da firma no começo da década de 1920". A nova organização também passaria por mudanças, tornando-se Sérgio \& Pinto em 1919, Álvaro Pinto \& Cia. em 1920, Alexandre Henault \& Cia em 1921, e, em 1925, foi adquirida por membros do Jockey Club do Rio de Janeiro e passou a chamar-se Empresa Almanack Laemmert Ltda. Pouco se publicou nesse período, com destaque para o Livro de ouro do centenário da independência do Brasil, obra de 500 páginas, com patrocínio do Governo Federal. Em 1942, um incêndio poria fim à longa existência do Almanak ${ }^{24}$, mas a Gráfica Laemmert continuaria até o ano de 1970, quando ainda publicou livros com esse nome.

24 O último número foi relativo ao ano de 1943. 


\section{À guisa de conclusão}

Pode-se concluir, uma vez percorridos os trajetos do Almanach royal e do Almanak Laemmert, dois anuários de relevante importância no "gênero", na França e no Brasil, que ambos se destacam pelo fragmentário das informações e do pensamento ali impresso. A diversidade de seções, cobrindo diferentes tópicos transcendem a própria forma do almanaque. $O$ fato é que a concepção e o formato do almanaque prenunciaram uma dissolução da totalidade justamente por querer buscá-la a todo custo, dando conta de tudo o que acontece em um país. Nisso, o Almanak Laemmert figura algo simbólico através de suas constantes organizações até tornar-se o Almanak do imperio do Brazil, almejando abraçar toda a informação. O resultado não podia ser outro, a dissolução da totalidade, que depois se fragmentou, tal como ocorre em nossos dias, quando a informação está estreitamente vinculada às novas tecnologias e seu desenvolvimento.

Fosse hoje na Internet, as seções seriam semeadas de hipertextos que talvez trouxessem às seções um fio condutor. Por outro lado, seria possível ver essa renovação não apenas como o surgimento de uma nova forma de condensação da informação em resposta a uma competição acirrada, mas também como uma reação real às pressões da modernidade, marcadas pelo surgimento e a presença simultânea de novas mídias, formando uma teia que exponencializa ainda mais o fragmentário caraterístico do almanaque.

Não por outra razão, publicações como o Almanach royal e o Almanak Laemmert agiram de forma fragmentada, refutando a estética clássica e totalizante, e por isso se tornaram tão populares. $\mathrm{O}$ fragmentário oferece a representação de um mundo incapaz de produzir suturas, em que o novo surge em oposição àquilo que é ou está e talvez aí resida a necessidade de os almanaques se constituírem de enfadonhas listas, elementos que buscavam a totalidade, haja vista 
pautarem-se primeiramente por listas de nomes que simbolizavam o esteio da sociedade que se queria imutável, perene, como tudo parecia ser durante o Classicismo. A maioria dos almanaques, a exemplo dos aqui analisados, estavam estreitamente ligados ao poder, em relação de coabitação, porém, ao se constituírem dessa forma, acabaram por oferecer uma reflexão sobre como a sociedade interagia com o fragmentário, corporificando-se através dos diferentes estratos sociais em busca da completude, não obstante, a cada lista, ficar clara a fragmentação desde a sua própria publicação.

Lançado em um mundo forjado por movimento, deslocamento e velocidade, afinal, a cada ano precisava ser revisto e reelaborado, o almanaque oferecia uma forma particular de agir sobre o mundo fragmentado. Sua densidade revelava um lembrete das singularidades que poderiam escapar a modos totalizantes de pensamento e a uma representação da espessura da modernidade em uma dinâmica do nada e do tudo. Quanto à sua concepção e leitura, por trás da aparência de distração e da praticidade das informações utilitárias fornecidas por esses almanaques, cujos fragmentos são organizados em série, nota-se que elas acabaram por construir uma espécie de fundo pictórico coletivo. Essas informações tomadas em série fortalecem e modificam a sociedade ao apresentar de forma demorada o que existia e o que já existe. A série do almanaque remete abertamente a uma construção da realidade, haja vista o leitor observar seus fragmentos de modo seriado, em um esforço de comparação com a realidade que conhece.

Por fim, vale ressaltar que o almanaque tenta representar uma espessura de realidade que nunca é completamente alcançada porque sempre procrastinada, algo que se pode notar tanto no Almanach royal quanto no Almanak Laemmert.

RECEBIDO: 25/08/2021 APROVADO: 05/09/2021 


\section{REFERÊNCIAS}

BARBIER, Jonathan. L'éducation du “peuple” par les almanachs au XIXe siècle. In : Carnet de la recherche à la Bibliothèque nationale de France. Bases de programmes de recherches, 1 mai 2020, s/p. Disponível em: https://bnf.hypotheses.org/9377. Acesso em: o9 de agosto de 2021.

CHARPENTIER, Louis-Pierre Manuel. La Bastille dévoilée: ou Recueil de pièces authentiques pour servir à son histoire. Vol. 1. Paris : Chez Desenne, libraire, au Palais-Royal, 1789.

COQUEREAU, Jean-Baptiste-Louis. Mémoires de l'abbé terrai, sa vie, ses intrigues et sa chute. Vol. I. Paris : À la Chancellerie, 1777.

GRAND-CARTERET, John. Les ALMANACHS français: 1600-1895. Paris : Alisie et $\mathrm{C}^{\text {ie }}$ Libraires-Éditeurs, 1896.

HALLEWELL, Laurence. O livro no Brasil: sua história. Tradução de Maria da Penha Villalobos, Lólio Lourenço de Oliveira e Geraldo Gerson de Souza. $2^{a}$ ed. São Paulo: EDUSP, 2005.

L'ENCYCLOPÉDIE. "Almanach ". 1 ${ }^{\text {re }}$. éd. Texte établi par d'Alembert et Diderot, 1751 , Tome I.

LAVISSE, Ernest. Histoire de France depuis les origines jusquà la Révolution. Vol. 2 : Louis XIV: histoire d'un grand règne, 1643-1715. Paris : Librairie Jules Tallandier, 1983.

LEPREUX, Georges. Gallia typographica. Répertoire biographique et chronologique de tous les imprimeurs de France depuis les origines de l'imprimerie jusqu'à la révolution. vol. I, partie 1. Paris : Librairie ancienne Honoré Champion, 1911.

LÜSEBRINK, Hans-Jürgen. Le livre aimé du peuple: les almanachs québécois, de 1777 à nos jours. Québec: Les Presses de l'université Laval, 2014.

MAGRI, Dirceu. Voltaire, percurso pelos trópicos. Rio de Janeiro: editora Vermelho Marinho, 2020.

MARQUES DE MELO, José. Jornalismo brasileiro. Porto Alegre: Editora Sulina, 2003.

MASSA, Jean-Michel. A juventude de Machado de Assis. Rio de Janeiro: Editôra Civilização Brasileira, 1971.

RENAUD, Henri-Paul-Joseph. L'origine du mot "Almanach » In : Isis. International review devoted to the history of science, XXXVII, $\mathrm{n}^{\circ} 107-108$, 1947, p. 44-46. 


\section{Almanaques/Sites consultados}

D'HOUTY, Laurent. Almanach Royal, ... présenté a Sa Majesté pour la première fois en 1699. Paris : De l'imprimerie de la veuve d'Houry \& Debure, 1746. Disponível em: https://books.google.com.br/books?id= geCaK $3 z \mathrm{HW}$ woC\&printsec $=$ frontcover $\& \mathrm{hl}=\mathrm{fr} \# v=$ onepage $\& \mathrm{q} \& \mathrm{f}=$ false . Acesso em 18/08/2021, às 19h3om.

LAEMMERT, Eduard; LAEMMERT, Heinrich. Almanak Laemmert. Rio de Janeiro, 1844 a 1899. Disponível em: http://objdigital.bn.br/acervo_ digital/div_periodicos/alman ak/almanak.htm. Acesso ao longo do mês de agosto de 2021.

La Langue française. Dictionnaire en ligne. Disponível em: https://www. lalanguefrancaise.com/dictionnaire/definition/almanach. Acesso em $14 / 08 / 2021$.

\section{Minicurrículo}

Dirceu Magri é Doutor em Letras pela Universidade de São Paulo (USPFFLCH) e Université Paris 1 - Panthéon Sorbonne; Membro da SFEDS - Société Française d'Étude du Dix-Huitième Siècle; pesquisador do GRUPEBRAF - Grupo de Estudos Brasil-França (IEA-SP); Pós-doutorando (Bolsista PNPD) na Universidade Federal de Viçosa-UFV; autor de De Borboletas e Colibris em sobrevoo: presença francesa nas crônicas machadianas (Editora FAP-Unifesp, 2016) e Voltaire, percurso pelos trópicos (Editora Vermelho Marinho, 2020). 